\title{
Salutarismo e medicalização da vida cotidiana
}

\author{
Healthism and the medicalization of everyday life
}

\author{
Salutarismo y la medicalización de la vida cotidiana
}

\author{
Robert Crawford $d^{1, a}$ \\ crawford@u.washington.edu \\ ${ }^{1}$ School of Interdisciplinary Arts and Sciences, University of Washington Tacoma. Tacoma, WA, Estados Unidos. \\ ${ }^{a}$ Doutorado em Ciências Política pela University of Chicago.
}

\section{Resumo}

Este artigo trata de algumas implicações da nova consciência de saúde e seus movimentos - de saúde holística e autocuidado - para a definição e solução de problemas relacionados à 'saúde'. O salutarismo representa um modo particular de considerar o problema da saúde e é característico desse novo tipo de consciência e de seus movimentos. Ele pode ser melhor entendido como uma forma de medicalização, no sentido de que ainda retém noções-chave da medicina. Assim como a medicina, o salutarismo situa o problema da saúde e da doença no nível do indivíduo, e as soluções são elaboradas no plano individual. Na medida em que o salutarismo dá contornos a crenças populares, continuaremos a ter uma concepção e estratégias de promoção de saúde apolíticas, e, portanto, sem efeitos. Além disso, ao conceder à saúde um estatuto de supervalor, uma metáfora para tudo o que há de bom na vida, o salutarismo reforça a privatização da luta por generalização do bem-estar.

Palavras-chave: Medicalização; Autocuidado; Bem-estar.

\begin{abstract}
This article considers some implications of the new health consciousness and movements - holistic health and self-care - for the definition of and solution to problems related to 'health'. Healthism represents a particular way of viewing the health problem, and is characteristic of the new health consciousness and movements. It can best be understood as a form of medicalization, meaning that it still retains key medical notions. Like medicine, healthism situates the problem of health and disease at the level of the individual. Solutions are formulated at that level as well. To the extent that healthism shapes popular beliefs, we will continue to have a non-political, and therefore, ultimately ineffective conception and strategy of health promotion. Further, by elevating health to a super value, a metaphor for all that is good in life, healthism reinforces the privatization of the struggle for generalized well-being.
\end{abstract}

Keywords: Medicalization; Self-care; Wellness. 


\section{Resumen}

Este artículo considera algunas implicaciones de la nueva conciencia de salud y movilización - salud holística y autocuidado - para la definición y solución de problemas relacionados con la 'salud'. El estilo de vida representa una forma particular de problema de salud, y es característico de la nueva conciencia de la salud y los movimientos. Puede entenderse mejor como una forma de medicalización, lo que significa que todavía conserva nociones médicas clave. Al igual que la medicina, la salud sitúa el problema de la enfermedad en el nivel del individuo. Las soluciones se formulan a ese nivel también. En la medida en que el sistema de salud moldee las creencias populares, seguiremos teniendo una no política, y por lo tanto, en última instancia ineficaz concepción y estrategia de promoción de la salud. Además, elevando la salud a un supervalor, una metáfora de todo eso es bueno en la vida, el saneamiento refuerza la privatización de la lucha por la generalización del bienestar.

Palabras-clave: Medicalización; Autocuidado; Bienestar.

Observações: A apresentação do texto foi adaptada aos padrões da Reciis. As notas aqui presentes abrangem as notas originais e agradecimentos do autor, assim como as observações adicionalmente feitas pelas tradutoras. Obras não publicadas à época, e que hoje se encontram disponíveis, tiveram suas referências atualizadas.

Licença CC BY-NC atribuição não comercial. Com essa licença é permitido acessar, baixar (download), copiar, imprimir, compartilhar, reutilizar e distribuir os artigos, desde que para uso não comercial e com a citação da fonte, conferindo os devidos créditos de autoria e menção à Reciis. Nesses casos, nenhuma permissão é necessária por parte dos autores ou dos editores. 


\section{Introdução}

O esforço social para controlar parte da experiência humana capturada pelo conceito de saúde permanece difícil de ser percebido. Este texto é a tentativa de avaliação de alguns esforços realizados no final dos anos 1970, nos EUA. Uma nova e popular consciência de saúde se difundiu em nossa cultura. O interesse por saúde pessoal tornou-se uma preocupação nacional. Cada vez mais esforço pessoal, atenção política e dólares estão sendo dispendidos em nome da saúde. Testemunhamos uma explosão da corrida e dos exercícios físicos, a emergência da retórica ética antitabaco, geralmente agressiva, a proliferação de revistas populares de saúde e a visibilidade, com frequência surpreendente, do tema saúde em jornais, revistas e propagandas, mesmo em anúncios de produtos remotamente relacionados ao assunto. Vitaminas e outros artigos de saúde foram mais consumidos, enquanto outros itens deixaram de sê-lo - todos por razões de saúde. Em inúmeras ocasiões sociais e apesar da suposta rejeição da preocupação com o assunto ou das brincadeiras relacionadas a isso, a saúde pessoal tornou-se um tema favorito de conversas.

Certamente não para todos. Os entusiastas da saúde, aqueles que proclamam e advogam um estilo de vida saudável, parecem ser majoritariamente da classe média. Enquanto as lutas das classes trabalhadoras para encurtar a semana de trabalho, abolir o trabalho infantil e mudar condições de trabalho historicamente têm tido a saúde como foco. Embora saúde ocupacional e segurança tenham gerado um novo interesse nas últimas décadas, a preocupação corrente com saúde pessoal exibe um selo distintivo - embora não exclusivo - da classe média. Isso é particularmente verdadeiro em dois novos movimentos de saúde, os quais receberam considerável atenção popular: saúde holística e autocuidado.

O movimento de saúde holística, do qual muitos dos exemplos deste texto são tirados, é um desafio notavelmente diverso e desafiador da medicina ortodoxa ${ }^{1-6}$. Inclui uma série de curadores não alopáticos e seus clientes e ainda maior conjunto de adeptos, os quais têm adotado muitos dos princípios da vida saudável. Alguns dos métodos de saúde utilizados são: terapias de redução de estresse, tais como meditação e biofeedback; terapias de polarização para 'equilíbrio da energia vital'; iridologia (interpretação da íris); imaginação guiada; terapias nutricionais; terapias de movimento ou dança; rolfing (técnica para reordenar o corpo); massagens e vários métodos de saúde emprestados da naturopatia, da homeopatia, de tradições americanas nativas e de tradições orientais ${ }^{7,8}$. A saúde holística vê a doença e a saúde não simplesmente como uma questão física, mas também emocional, mental e espiritual. Interessados no indivíduo por inteiro, como um todo, os curadores holísticos falam de tratar a pessoa e não a doença. Orientados em direção à promoção de saúde ou à prevenção de doença, eles "[...] querem saber como as pessoas que vêm até eles vivem e sentem, o que comem e fumam e quanto exercício fazem, o tipo de estresse que elas têm no trabalho e em casa, se estão satisfeitas com suas realizações e suas relações com outras pessoas. [...] Grande parte do seu trabalho terapêutico consiste em ajudar as pessoas a ver como seus hábitos, atitudes e expectativas, a maneira como vivem e trabalham, pensam, e sentem, estão afetando sua saúde física e emocional, e ajudá-las a tomar medidas não só para prevenir a doença, mas para se sentir melhor”.

Em sua orientação filosófica mais ampla, a saúde holística é retratada como 'um modo de ser', uma interrelação ou equilíbrio entre corpo, mente e espírito, um interesse de 'alto nível de bem-estar', uma 'super-saúde' ou uma 'alegria de viver'. Frequentemente, a saúde holística incorpora a visão religiosa, e ambos, praticantes e organizações religiosas do Oriente e do Ocidente, têm promovido serviços de saúde holística. Em todas as suas manifestações, a saúde holística encoraja os clientes a tornarem-se participantes ativos nos processos de saúde e a exercerem a autorresponsabilidade. Os movimentos de saúde holística têm muito em comum com outro movimento de saúde dos anos 1970. 
Assim como a saúde holística, os movimentos de autocuidado e ajuda mútua i são também caleidoscópicos em sua abordagem de preocupação sobre saúde e doença ${ }^{9-16}$. Ao contrário da saúde holística, há pequena atenção com o desenvolvimento de métodos alternativos de cura ou de novos curadores profissionais, mas, assim como a saúde holística, esses movimentos frequentemente desafiam a medicina profissional. Buscam reduzir a confiança dos indivíduos nos profissionais médicos e substituí-los por atividades de indivíduos e grupos com objetivo de melhorar a saúde, lidando com doenças crônicas, adquirindo habilidades diagnósticas e terapêuticas, e adotando práticas de prevenção de doenças. O autocuidado é mais orientado para transferir a competência médica para o indivíduo. Ozonoff e Ozonoff ${ }^{16}$ descrevem a literatura de cuidado médico em várias categorias: "primeiro socorro", "triagem", "substituto médico", "autoaperfeiçoamento" e "guias de consumo". Como definido por Levin ${ }^{17}$, um dos seus maiores proponentes, autocuidado é "um processo pelo qual um leigo pode atuar em seu próprio favor na promoção de saúde, na prevenção e detecção da doença e no tratamento no nível do recurso primário de saúde no sistema de saúde”. A ajuda mútua ${ }^{\text {ii }}$ faz muitas das mesmas coisas, mas em grupos. Ela se desenvolve mais de uma tradição de autoajuda enquanto auxílio recíproco. No caso das mulheres, a ajuda mútua é claramente uma estratégia dentro do contexto de um movimento político ${ }^{18}$. Em muitos exemplos concretos, no entanto, ajuda mútua e autocuidado tornam-se quase indistinguíveis.

Este artigo é uma discussão sobre algumas das implicações de uma maneira particular de visão do problema de 'saúde'. Um trabalho anterior ${ }^{19,20}$, dedicado a analisar a ideologia da responsabilidade individual pela saúde, relacionou essa ideologia com os desenvolvimentos na economia política do setor médico e na sociedade americana em geral. Debruçou-se sobre as implicações políticas e funções simbólicas da ideologia na resolução de questões emergentes em favor de interesses políticos e econômicos dominantes. Sem pretender minimizar essas preocupações, o presente trabalho é um exame mais aprofundado e mais amplo da estrutura dessa ideologia. Enquanto os anteriores foram mais voltados para a elaboração dos usos instrumentais ou funcionais da ideologia, este é uma tentativa de identificar alguns dos conceitos e suposições da nova consciência de saúde. Como uma discussão de ideologia - termo que entendo como uma maneira socialmente construída de ver, interpretar e avaliar alguns aspectos do mundo físico e social, e a relação consigo próprio e com esses mundos - este texto aborda as seguintes questões: $\mathrm{O}$ que explica como o problema de 'saúde' é entendido em um momento histórico particular? Qual é o processo pelo qual as culturas definem determinadas atividades individuais e coletivas como essenciais para a saúde? Por que outras atividades são excluídas ou negligenciadas? Estas são algumas das questões mais importantes e complexas para uma análise política da forma como as sociedades tentam resolver os problemas relacionados com o conceito de saúde.

As ideias aqui apresentadas são exploratórias e heurísticas. O artigo não é um relato descritivo desses movimentos ou de outras manifestações concretas da nova consciência de saúde. Ele deve ser sucedido por uma pesquisa etnográfica ("a reconstrução do saber do senso comum na atividade cotidiana e na interação social”¹). Além disso, embora as observações a seguir assumam a forma de uma crítica, eu particularmente espero que sejam consideradas pelos proponentes da nova consciência de saúde e não simplesmente por seus críticos. Se, em nosso entusiasmo por mudanças orientadas para a criação de novas capacidades individuais e sociais livres de dominação, não somos capazes de identificar aspectos que podem contradizer esses objetivos, corremos o risco de sucessivas falhas. Mesmo os desafios mais radicais da ortodoxia são, na melhor das hipóteses, parciais, e sempre contêm em suas concepções e estrutura os próprios elementos contra os quais

\footnotetext{
i Nota das tradutoras (NT): o termo original é self help, utilizado por Crawford para referir-se a grupos de ajuda recíproca e auxílio mútuo que, geralmente, possuem características terapêuticas, tais como Alcoólicos Anônimos e outros grupos de discussão e compartilhamento de problemas relativos à saúde física e psíquica.

ii A discussão que se segue é mais relevante para o autocuidado do que para a ajuda mútua, e mais relevante para os aspectos de autocuidado concernentes à saúde, promoção e prevenção de doenças.
} 
os desafios são propostos. No processo, as ideologias dominantes e estruturas sociais são reproduzidas. A partir de manipulações externas ou de concepções internas (de certa forma uma falsa dicotomização), os movimentos contêm contradições ideológicas desde seu início. Afinal, eles se desenvolvem dentro de um espaço ideológico que já é construído. Tais contradições não podem ser motivo para deixar de lado a questão, mas também não podem ser ignoradas.

\section{Salutarismo e a nova consciência de saúde}

Escolhi a palavra salutarismo ${ }^{\text {iii }}$ como forma de cristalizar algumas importantes contradições da nova consciência de saúde e dos movimentos por ela orientados (para um uso anterior, consulte Irving Zola ${ }^{22}$ ). Em linhas gerais, salutarismo é definido aqui como a preocupação com a saúde pessoal como foco primário - muitas vezes 'o' principal foco - para a definição e realização do bem-estar. Um objetivo que deve ser atingido primeiramente por meio da modificação de estilos de vida, com ou sem ajuda terapêutica. A etiologia da doença pode ser vista como complexa, mas o salutarismo trata do comportamento individual, de atitudes e emoções como sintomas relevantes que necessitam de atenção. Os salutaristas reconhecerão, em outras palavras, que os problemas de saúde podem ter origem fora do indivíduo, por exemplo, na dieta americana, mas, uma vez que estes problemas também são considerados comportamentais, as soluções são encontradas no plano das escolhas individuais, por isso, eles exigem acima de tudo a suposição de responsabilidade individual. Para o salutarista, a solução repousa na determinação do indivíduo para resistir à cultura, à publicidade, aos constrangimentos institucionais e ambientais, aos agentes de doenças ou, simplesmente, aos hábitos pessoais preguiçosos. Em essência, então, a causa fica ao alcance individual, e a solução é criada dentro do mesmo espaço estreito.

A nova consciência de saúde é mais abrangente do que aquilo que é descrito aqui como salutarismo. A ampliação do interesse por saúde muitas vezes inclui preocupações ambientais e de saúde ocupacional, bem como preocupação com melhoria da saúde pessoal. A consciência ambiental tem sido especialmente importante para o chamado movimento de saúde natural. Pode-se também encontrar na nova consciência de saúde pessoas com desenvolvido entendimento político acerca de como forças sociais encorajam sistematicamente o comportamento individual não saudável, muitas vezes para proveito privado. Tabaco e alimentos produzidos pelo agronegócio têm sido objetos de muita preocupação. A nova consciência de saúde, em outras palavras, é um emaranhado complexo e não pode ser reduzida à corrente do salutarismo ou qualquer outra coisa. Os modos como pensamos e agimos em relação às nossas ansiedades e esperanças em saúde, a nossa compreensão do que deve ser feito para promover ou manter a saúde, nossas noções de prestação de contas e responsabilidade estão ali, em fluxo. Assim, o foco sobre a saúde pessoal e modificações no estilo de vida pode coexistir e até mesmo interferir para estimular tentativas de mudanças nas condições sociais prejudiciais para a saúde de todos. Como Katz e Levin ${ }^{23}$ e Gartner e Riessman ${ }^{10}$ apontam a respeito do autocuidado e da ajuda mútua, há exemplos numerosos de grupos politicamente ativos que se identificam com estes movimentos.

Dessa forma, embora o salutarismo possa não dominar completamente as ideologias e a gama de atividades de grupos e indivíduos que se consideram parte desta nova consciência de saúde, o argumento aqui é que, em certa medida, esta tendência ideológica está presente em todos eles. Vou argumentar que a ideologia do salutarismo promove uma despolitização contínua e, portanto, mina os esforços sociais para melhorar a saúde e o bem-estar. Como uma ideologia que promove a elevada consciência de saúde, juntamente com o

iii NT: Originalmente, o termo é healthism. Por tratar-se de neologismo criado pelo autor para ressaltar a saúde como principal foco de atenção, a palavra não possui correspondência em português. Optou-se por salutarismo e salutarista como traduções para healthism e healthist. Salutarismo, entretanto, também é um neologismo. 'Salutar' em português significa o que é conveniente ou o que é bom para a saúde, além de edificante ou moralizador do espírito. Essa palavra vem do latim salutaris, derivada de saulus, que denota tanto saúde como salvação. No meio acadêmico italiano e espanhol, a obsessão com a saúde de um modo salvacionista foi traduzida como salutismo. Na França, vem sendo utilizado o termo santéisme. Ainda que 'salutarismo' não traduza healthism de modo idêntico, consideramos mais adequado por refletir as principais concepções que o autor propõe no texto. 
autocontrole pessoal e a autotransformação, pode ser benéfica para aqueles que adotam um estilo de vida mais promotor de saúde ${ }^{24}$. Mas, no decorrer do processo, pode também servir à ilusão de que podemos controlar nossa própria existência 'individualmente' e que, adotando ações individuais para melhorar a saúde, podemos satisfazer as mais variadas e complexas necessidades. Assim, o salutarismo funciona como ideologia dominante, contribuindo para a proteção da ordem social do exame, da crítica e da reestruturação, que poderiam ameaçar aqueles que se beneficiam da doença, da miséria e da morte de outros.

O modo como a saúde é popularmente entendida em grande parte reflete-se na terapêutica de uma sociedade. Estas terapias, por sua vez, estruturam modos de entendimento culturais ${ }^{25}$. Noções populares sobre saúde, em outras palavras, ajudam a produzir o modo terapêutico e são parcialmente reproduzidas por ele. Vivemos em uma era médica. A cultura norte-americana tem passado por uma progressiva medicalização, a qual pode ser compreendida parcialmente pelo fato de a medicina incorporar algumas das proposições e características mais fundamentais dessa cultura. A menos que estas propostas sejam compreendidas, não será possível combater a medicina como uma instituição, mas se deixará intacto (ou se reforçará) o mundo cultural que ela 'representa'.

O profundo impacto da medicina nas crenças e atividades de nossas sociedades capturou a atenção de numerosos observadores da vida social americana ${ }^{26-30}$. Contrária inicialmente às reivindicações e impressões medicalizadoras, a nova consciência de saúde (nas suas mais saudáveis manifestações) implica outro tipo de medicalização da nossa cultura, e, em particular, uma medicalização do entendimento do problema de saúde. Embora modificações de práticas e de paradigmas médicos dominantes estejam sendo adotadas, algumas das concepções culturais médicas mais centrais e problemáticas da cultura dominante têm permanecido intocadas.

\section{Medicalização como ideologia}

Medicalização, conceito desenvolvido pelo sociólogo Irving Zola ${ }^{31}$, pode ser entendida como tendo dois significados amplos. O primeiro liga uma gama crescente de fenômenos sociais com a instituição da medicina - com a profissão de medicina, com a terapêutica prática e o diagnóstico médico. Neste uso, a medicalização é geralmente descrita como uma expansão do poder profissional médico sobre esferas mais amplas da vida, especialmente sobre os comportamentos desviantes, substituindo os atores religiosos e legais e seus modos de controle social. Como profissionais médicos ampliam continuamente seu âmbito de ação, os recursos sociais dedicados às atividades assumidas por médicos também aumentam, e estes se tornam guardiões de um número cada vez maior de funções sociais que conferem tanto benefícios e penalidades, quanto privilégios e exclusões ${ }^{32}$. Zola ${ }^{22}$ argumenta que a medicalização, nesse sentido, está conectada com dois atributos da profissão: "o controle de seu próprio trabalho e sua tendência a generalizar seu conhecimento além dos assuntos de conhecimento técnico". De fato, como é característico, de acordo com Hughes apud Zola ${ }^{21}$, que descreve os profissionais: "Os praticantes, individualmente, não apenas fazem coisas que os outros não fazem, com o objetivo de serem admitidos no dileto círculo de colegas, mas também, coletivamente, assumem a presunção de dizer à sociedade o que é bom e o que é certo para o indivíduo e para a sociedade em algum aspecto da vida. Na verdade, eles definem os próprios termos em que as pessoas podem pensar acerca deste aspecto da vida".

O segundo significado da medicalização refere-se à extensão do leque de fenômenos mediados pelos conceitos de saúde e doença, muitas vezes com foco na importância desse processo para o entendimento do controle social do desvio. Como Illich ${ }^{27}$ notou: "Ao nomear o espírito que subjaz ao desvio, a autoridade coloca o desviante sob o controle da linguagem e dos costumes, desse modo, ele passa de uma ameaça, a um apoio ao sistema social. A etiologia é socialmente autorrealizável”.

A existência social é cada vez mais limitada pela nomenclatura médica desse espírito. Mais comportamentos desviantes são definidos como doença ou normalidade em termos de saúde. Alcoolismo, abuso de crianças, dependência de opiáceos, obesidade, mau funcionamento sexual e violência têm se 
tornado objetos de diagnóstico médico e recebido o rótulo de doença ${ }^{33}$. É também digno de importância que, conforme nossa sociedade se torna cada vez mais preocupada com a prevenção de doenças e a promoção da saúde, mais atividades sociais são pensadas em relação aos seus efeitos sobre a saúde. Em outras palavras, a prevenção da doença torna-se um padrão altamente difundido pelo qual os comportamentos - comer, beber, trabalhar e as atividades de lazer - são julgados.

Claro que os dois significados gerais estão ligados. As categorias de saúde/doença que têm sido promovidas pelos profissionais, diretamente ou indiretamente, aumentaram o poder profissional. Ou seja, a medicalização no primeiro sentido promove a medicalização no segundo, e vice-versa. Freidson capta a essência dessa interligação ${ }^{26}$. "A profissão médica tem reivindicado a jurisdição sobre o rótulo de doença e nada mais pode ser acrescentado, independentemente da sua capacidade de lidar efetivamente com ela. De maneira que a ascensão de um valor social tal como a saúde é inseparável do surgimento de um veículo para o valor - um corpo organizado de trabalhadores que reivindicam autoridade sobre esse valor. Uma vez que a jurisdição oficial ganhou, a profissão é, então, propensa a criar sua própria noção especializada do que seja chamado de doença. Enquanto a medicina é dificilmente independente da sociedade em que ela existe, ao tornar-se um veículo para os valores da sociedade, ela desempenha um importante papel na formação e na formatação dos significados sociais presentes em tais valores".

Um forte argumento pode ser usado, de que a nova consciência em saúde e seus movimentos podem expandir a competência médica para vários setores, mesmo que eles estejam atualmente desenvolvendo relativa autonomia em relação a ela ${ }^{16,34}$. Isso é secundário, no entanto, para o meu tema. Basta dizer que o poder da profissão médica e da extensão de competência profissional deve ser distinguido do poder de uma forma de pensar que está ligada, mas também separada, da profissão médica - a disseminação cultural da percepção ou ideologia médica. O foco aqui é a influência da visão médica, com o impacto de um já medicalizado entendimento social sobre as concepções e práticas emergentes, que assimilou o autocuidado, a saúde holística e a nova consciência de saúde. A intenção é seguir Hughes ${ }^{22}$ quando fala de profissões que "estabeleceram os vários termos a partir dos quais as pessoas podem pensar sobre saúde".

O que está sendo sugerido é que as noções de saúde e doença da cultura americana contemporânea em grande medida mantêm um significado medicalizado, em qualquer contexto utilizado. É no nível do cotidiano externo às instituições médicas que os relacionamentos, experiências, atividades e ideologias sobre a saúde estão sendo elaborados. O impacto da medicina deve ser examinado nesse nível, pois há profundas implicações no modo como nossa sociedade geralmente tenta resolver os problemas de saúde e bem-estar. A questão da medicalização é importante porque, como qualquer outro modo de simbolização, a percepção medicalizada estabelece limites sobre as formas de pensamento e canais de consciência e comportamento. Na medida em que os novos movimentos de consciência de saúde incorporam a ideologia médica, correm o risco de reproduzir muitos dos problemas sociais engendrados por essa forma terapêutica.

\section{Aspectos da percepção médica}

Como uma ciência clínica ou terapêutica, a medicina localiza o problema da doença no corpo individualiv . O indivíduo é, simultaneamente, o lugar da percepção e da intervenção, mais fortemente desde o final do século XVIII, quando, conforme Foucault ${ }^{36}$, o fundamento do conhecimento médico torna-se alojado na "soberania do olhar", fixado em sinais e sintomas individuais e, em seguida, na profunda estrutura anatômica. É através da observação dos sinais e sintomas individuais que se tornou "possível designar um estado patológico [...] uma essência mórbida [...] uma causa imediata" ${ }^{6}$. Com o desenvolvimento da anatomia, o entendimento médico da doença ficou mais totalmente dirigido para o "profundo, visível, sólido, fechado, mas acessível espaço

iv A doença é localizada no corpo do indivíduo e, assim, cria a necessidade para uma resposta de cura para aquela experiência individual. É este fato que subjaz ao problema ideológico que está sendo discutido. Veja, a seguir, nas seções "O impacto das práticas médicas" e "Saúde e subjetividade". Consulte também Jacoby ${ }^{35}$. 
do corpo humano"36. Assim, o que se conhece sobre a doença é agora assunto de conhecimento positivo do indivíduo. O que se vê é o que é conhecido, que, por sua vez, torna-se o espaço de intervenção. Trancado em uma forma particular de visão, um aprisionamento reforçado por estruturas institucionalizadas, a medicina conhece e age sobre a doença limitada por um imediatismo de percepção que é física (mecânica, bioquímica, visual). Para escapar de uma nosologia de essências mórbidas, ela construiu sua ciência e prática clínica em razão próxima do que se torna, em princípio, uma ocorrência observada dentro do corpo do indivíduo.

As noções de causalidade são comprimidas e restritas aos limites do indivíduo, no qual a doença assume sua única existência significativa. Qualquer coisa que não pode ser mostrada na interação com o organismo para produzir um estado mórbido é cada vez mais excluída. "O espaço local da doença é também, imediatamente, um espaço causal”"36. A solução para o problema da doença é dirigida para quebrar o nexo de causalidade mais imediato. Assim, a percepção médica empurra a solução para a compreensão causal imediata e local, para a eliminação dos sintomas e o restabelecimento dos sinais normais. Como Foucault ${ }^{35}$ declara, "o espaço da doença é, sem dúvida, o próprio espaço do organismo". Medicina tornou-se 'uma ciência do indivíduo'. Foucault contrasta o pensamento médico com uma tradição de percepção epidemiológica ${ }^{36}$, que vê o problema da doença como "um núcleo de circunstâncias", um "conjunto complexo de intersecções", no qual a única individualidade é a "individualidade histórica"29.

A noção médica intimamente ligada e muito discutida é a de etiologia específica ${ }^{29}$. Trata-se de um conceito de causalidade reducionista sugerindo que a doença pode ser entendida em termos de agentes patogênicos. A etiologia específica tem trabalhado para reforçar o individualismo médico, um individualismo que progressivamente demoliu as explicações fundamentadas em uma multiplicidade de causas. Auxiliados por nova tecnologia de pesquisa, os cientistas do final do século XIX foram capazes de isolar os microrganismos ativos de doenças infecciosas. Modelos explicativos poderosos foram construídos a partir de tais descobertas. A medicina científica atingiu a maioridade. As concepções mais vagas e metafísicas foram varridas, mas também foram desacreditadas as teorias da 'medicina social'. Como proclamado por um proeminente pesquisador médico alemão no final do século XIX, "o estudo de doenças infecciosas pode agora ser perseguido firmemente sem ser desviado por considerações sociais e reflexões sobre política social”37.

Experimentos de laboratório bem-sucedidos baseados no modelo etiológico médico foram erroneamente oferecidos como prova da supremacia da teoria particular de causalidade. A medicina científica havia conseguido esclarecer um elemento chave da causa das doenças, mas o esclarecimento serviu para concentrar a busca da causalidade onde a medicina científica agora alegou ser o campo próprio de investigação.

Foi apenas recentemente que a abordagem médica para a manutenção e promoção de saúde foi amplamente questionada no meio acadêmico e em círculos político ${ }^{38-40}$. Ninguém argumenta que a medicina é uma ferramenta terapêutica sem importância. Ela salva vidas e alivia a dor, permite vidas ativas e executa importantes funções 'de cuidados' (iatrogenia clínica à parte). No entanto, a conhecida incapacidade da medicina para encontrar uma cura para muitas das doenças crônicas e degenerativas - especialmente, doenças cardíacas, derrame e câncer -, combinada com a crise de custo da medicina e a acumulação de dados, que até questionam a contribuição da medicina para o declínio da mortalidade por doenças infecciosas ${ }^{38,41}$, tem forçado as discussões políticas sobre a consideração de estratégias mais eficazes de prevenção da doença.

\section{O impacto das práticas médicas}

Conceitos médicos são reforçados por uma prática terapêutica que isola o indivíduo a partir do contexto social em que a doença é adquirida. Claro que os modos de cura, as instituições terapêuticas e as práticas estão intimamente ligados com noções dominantes do que é, precisamente, ser curado. Nas diversas culturas, eles 
assumem formas radicalmente diferentes ${ }^{42}$. O impacto da prática terapêutica institucionalizada é reforçar formas dominantes de visão. A prática médica na América do século XX oferece um bom exemplo.

Muitas páginas foram escritas sobre a construção social e a experiência prática terapêutica. Apenas alguns pontos precisam ser ressaltados. Primeiro, deve estar claro, após décadas de investigação sociológica, que o encontro terapêutico é uma experiência de reestruturação ou socialização e, por conta de várias características da interação médico-paciente e do estado psicológico no qual a terapia é experimentada, ela é extremamente poderosa. Como Dewar ${ }^{43}$ e McKnight ${ }^{44}$ notaram, a pessoa torna-se um cliente e um paciente em um acordo contratual particular entre os dois, exigindo de ambos, entre outras coisas, a apresentação de "uma condição cuja patologia coincide estreitamente com a qualidade específica do modo de tratamento onde a entrega está sendo oferecida" ${ }^{3}$. Esta correspondência é conseguida através de um reordenamento da compreensão do problema pelo paciente. Na relação terapêutica, a tarefa do paciente é compreender os sinais e sintomas do problema conforme a leitura médica e, assim, aceitar a definição médica tanto para o problema como para a solução. Taussig 45 chama esse processo de criação de uma "objetividade fantasma" no que diz respeito à doença, um processo de "negar as relações humanas encarnadas em sintomas, sinais e terapia", um processo pelo qual "nós não só mistificamos relações sociais, mas também reproduzimos uma ideologia política sob o disfarce de uma ciência (aparentemente) das 'coisas reais' - coisas biológicas e físicas". Seguindo Lukacs, Taussig conclui que 45 "A prática médica é uma forma singularmente importante de manter a negação quanto à factibilidade social da realidade. Coisas assim assumem vida própria, separadas do nexo social que realmente lhes dá vida, e permanecem bloqueadas na sua própria constituição".

Os entendimentos que são reestruturados no encontro médico não devem ser compreendidos como previamente autônomos, uma vez que são manipulados na terapia. Experiências passadas e noções terapêuticas derivadas de ideias médicas difundidas, bem como premissas ideológicas adquiridas por outros meios e que reforçam o status quo, estruturam o encontro antecipadamente. O cliente já é, em certo sentido, medicalizado. Em outras palavras “as pessoas que estão sendo ajudadas assumem como próprias algumas das teorias, suposições e explicações de seus cuidadores" 3 . Essas atitudes são reforçadas perpetuamente em um ambiente terapêutico divorciado da família, amigos, casa e bairro, por relações hierarquicamente estruturadas em que a experiência e pressuposições não médicas são declaradas ilegítimas ou são efetivamente ignoradas. É uma prova irrefutável da força e da necessidade de uma explicação socialmente significativa, e da pobreza da prática médica, que as noções não terapeuticamente derivadas e os entendimentos que colocam a causa do infortúnio na experiência social concreta persistam.

Em suma, a prática médica é uma modalidade de tratamento individualizado, uma forma que define o cliente como deficiente e que reconstrói a compreensão do indivíduo e do problema para o qual a ajuda está sendo procurada. Esta reconstrução individualiza e compartimentaliza o problema, transformando-o em sua propriedade mais imediata, isto é, as manifestações físicas e biológicas do indivíduo doente, do corpo humano. A resposta para o problema é então logicamente mantida para encontrar o mesmo tratamento individualizado e profissionalizado, e não o reordenamento das circunstâncias sociais, políticas e ambientais nas quais o indivíduo existe. A necessidade de uma resposta terapêutica para a experiência individual da doença - que não é negada aqui -, torna-se um campo no qual as explicações seletivas são autoritariamente comunicadas e as relações sociais dominantes são, assim, reproduzidas. O espectro de uma sociedade medicalizada e medicada, onde drogas psicoativas, soníferos e apaziguadores de dores comuns (analgésicos) têm se tornado a resposta padrão para quase todos os mal-estares imagináveis, deve pelo menos levantar dúvidas quanto à sensatez de tal forte confiança sobre a solução médica do problema. Tais questões estão, de fato, sendo questionadas pelos novos movimentos de saúde. 


\section{Salutarismo e medicalização}

Adeptos da saúde holística e do autocuidado criticam e rejeitam muitas destas concepções e práticas médicas. $\mathrm{O}$ autocuidado sedimenta muito de sua filosofia em uma crítica das qualidades incapacitantes da nossa cultura pan-terapêuticav . Apesar de alguma profissionalização do movimento, o autocuidado visa a reduzir a dependência de médicos e outros profissionais da área de saúde, melhorar a autocompetência e, em suas formas de reuniões de autoajuda, estimular a ajuda mútua e o apoio. Pelo menos, no último caso, a ajuda mútua é um passo importante para voltar a integrar a experiência da doença em um contexto social significativo. Ao reconhecer a solidão da dor, da invalidez e da morte, os grupos de ajuda mútua fornecem uma alternativa viável às isoladoras experiências médicas.

Da mesma forma, o entusiasmo com a saúde holística pode ser entendido, em grande parte, como uma resposta à alienação experimentada no encontro médico, à incapacidade estrutural da medicina de fornecer explicações satisfatórias para as perguntas: ‘Por que eu?' e 'Por que agora?’. A concepção holística rejeita a destruição médica da interpretação fundamentada socialmente e, em vez disso, oferece um entendimento abertamente experimental da doença. Substitui o mundo estéril dos fatos biológicos por um sistema moral facilmente compreendido: um sistema de atitudes e comportamentos corretos, no qual 'a conexão entre nós e nossa experiência' é explicitada. Nesse processo, o significado social é reconstituído. "Qual é a mensagem desses sintomas?" pergunta o terapeuta holístico ${ }^{47}$; “O que é uma dor de cabeça para mim?” A ênfase da nova cura, argumenta-se, "deve ser deslocada da clínica para o foro pessoal”"46. A cura holística leva a sério a necessidade de o doente sofredor compreender sua dor e seu sofrimento em termos de todos os acontecimentos e experiências da vida cotidiana.

Não obstante, a saúde holística parece estar sobrecarregada pela ideologia do salutarismo. Mesmo se as pessoas por inteiro e suas experiências despertassem nova atenção e a múltipla causalidade substituísse a teoria médica de etiologia específica, mesmo se o dualismo corpo-mente fosse renunciado, abrindo caminho para concepções mais amplas ${ }^{\text {vi }}$ e modificações significativas, ainda assim, o problema estaria na formulação salutarista que situa o problema no nível individual da mente e do corpo ${ }^{49}$ : "Na perspectiva holística emergente, a natureza é um amigo interativo e a doença é um processo de resposta dentro do sistema de escolhas do indivíduo, um processo que informa o indivíduo que algo em sua vida está fora de curso. O indivíduo é a única pessoa que pode descobrir a mensagem de resposta e agir sobre ela, talvez com a ajuda de profissionais".

Como ideologia ligada à definição médica do problema de saúde e doença, na qual o indivíduo é o locus da percepção e intervenção, no salutarismo a saúde permanece trancada em uma prisão de reducionismo, apesar de sua aparente ampliação. O salutarismo leva as modificações das noções médicas da causalidade para uma direção única: o psicobiologismo, em direção à resistência e adaptação. Através dos conceitos de desarmonia, desequilíbrio, estresse, resistência, sistemas de imunidade, comportamentos de risco, inaptidão vii, estilo de vida saudável, plenitude, 'baixo nível de mal-estar' e 'alto nível de bem-estar', 'formas de ser e de perceber', e assim por diante, salutarismo é uma ideologia que requer a restruturação das próprias atitudes, emoções e comportamentos ou a intervenção de curadores para ajudar a realizar o mesmo. 'A doença é uma mensagem que vem de dentro', diz o bordão, tanto a causa quanto a cura podem ser encontradas lá. De acordo com um adepto ${ }^{50}$ : "Se quisermos ajudar indivíduos a reavaliar certas crenças importantes sobre eles mesmos e suas

\footnotetext{
V A distinção entre terapêutica e não terapêutica é cada vez mais difícil de perceber. Na prática, a terapêutica entendida como a prestação de um serviço por um 'curador', é difundida na sociedade através de um dilúvio de conselhos de profissionais e 'especialistas', encontrados nas publicações populares de saúde, lojas de comida saudável e propagandas de produtos consumidos em massa. Temos nos tornado o que Rieff ${ }^{46}$ descreve como uma "cultura terapêutica".

vi $\mathrm{O}$ artigo de Hayes-Bautista e Harveston ${ }^{48}$ propõe que "no modelo holístico de saúde o locus de causalidade e cura é ampliado para incluir a sociedade em geral". Os autores ressaltam a importância de curar não só o indivíduo, mas também "a sociedade que cria o indivíduo doente". Embora promissora, essa concepção não representa a direção tomada na esmagadora maioria da literatura.

vii NT: o termo original é unfitness.
} 
autoimagens, então estamos indo para o cerne das 'causas' básicas da doença”. "Reações diferentes para os mesmos fatores de estresse são, obviamente, determinadas pela nossa programação mental. São produto da forma como vemos o mundo e como pensamos que somos ameaçados por ele. Para mim, portanto, faria muito mais sentido examinar e reverter formas negativas como percebemos o mundo do que gastar tempo e dinheiro inventando novas pílulas para o alívio do sofrimento. Pílulas dão alívio, mas apenas adiam a cura. A 'cura' só ocorre a partir da reversão de nossas percepções e da descoberta de como criamos nossas próprias 'realidades”' (destaques acrescentados pelo autor) ${ }^{19,20}$.

Não se trata de apontar a irrelevância desta acepção de saúde, mas apenas de ressaltar que o modelo biomédico também deve ser apreciado naquilo que tem contribuído para a cura e a prevenção. Como modelo terapêutico, a saúde holística pode provar ser tão eficaz como a medicina (e talvez mais eficaz para muitas situações). Afinal, a saúde e a doença podem ser vistas também como questões individuais. Seja qual for o nível de construção social para o qual a causalidade possa ser atribuída, a construção aparece em formas que são exclusivamente individuais. Pelo menos são experimentadas como tal. É possível e importante desmascarar o significado de saúde e da doença em termos mais pessoais. Além disso, pode-se sempre colocar um momento de escolha, atos e atitudes de cumplicidade, um nível de responsabilidade e de controle individual. Ignorar a parte psíquica e comportamental da saúde e da doença seria por si só reducionista. Provavelmente também impediria uma vasta gama de possibilidades preventivas e terapêuticas.

Mas se o ‘significado’ de saúde e de doença permanece divorciado da sociedade na qual é construído, a resolução do problema deve ser parcial, condenada a esforços de melhoramento ou de adaptação, ou mesmo a ilusão de autonomia pode ser mais facilmente nutrida. Ilustrativa é uma introdução a uma caderneta de saúde holística na qual o autor aconselha ${ }^{51}$ contra o 'negativismo' de culpar o meio ambiente e proclama que "a saúde e a felicidade podem ser nossas; se quisermos, podemos criar a nossa realidade pessoal, até no mais ínfimo pormenor”. Quando esses esforços privados tornam-se o modelo para a prática social, abandonando as políticas públicas, reforçam a medicalização da vida, deixando-nos impotentes para controlar nosso próprio destino. Eles nos incapacitam precisamente porque, tanto na concepção quanto na prática, aqueles que adotam esses esforços como modelo tendem a negar ou optar por ignorar as condições estruturais que produzem em nossa sociedade os comportamentos, atitudes e emoções sobre os quais muita atenção está agora centrada.

Igualmente ilustrativo é um popular guia de autoajuda para superação de câncer ${ }^{52}$. Depois de oferecer lamentavelmente poucas observações sobre a realidade de substâncias cancerígenas, os autores imediatamente procedem a uma discussão de como poucas pessoas expostas a agentes cancerígenos, na verdade, contraem câncer. Partindo desta constatação, o resto do livro é dedicado a temas como "personalidade, estresse e câncer", "um modelo mente/corpo de desenvolvimento de câncer", "participar da sua saúde", "aceitar a responsabilidade por sua saúde", "benefícios da doença”, "o valor das imagens mentais positivas”, "encontrar o seu guia interior de saúde", e assim por diante. Apenas referências mais vagas são feitas aos fatores culturais e sociais dominantes que promovem a "personalidade propensa ao câncer".

Tal como no exemplo anterior, origens sociais não são inteiramente negadas. Na verdade, a saúde holística rejeita "o estudo do indivíduo abstraído do contexto de outros seres humanos". Mas, como Jacoby escreveu sobre grande parte da psicologia contemporânea, o contexto social é mais frequentemente reduzido ao contexto imediato interpessoal das relações e “atmosferas psicológicas”. Ele observa35: “A constelação social está banalizada por uma rede humana imediata. Esquece-se que a relação entre 'mim e você' ou 'sua família e você' não se esgota no imediato: toda a sociedade está presente nela”.

Assim, Ardell ${ }^{53}$ dedica um capítulo de seu livro High Level Wellness para "uma sensibilidade ambiental". Depois de observar brevemente os aspectos físicos e sociais do ambiente, sobre o qual ele adverte que "há limites severos para o que a maioria de nós pode fazer para mudar", ele dedica praticamente todo o capítulo para o que ele chama os aspectos "pessoais" do meio ambiente ${ }^{53}$ : "A maneira como você organiza seu quarto de dormir ou espaço de trabalho, os tipos de redes de amizade que você cria e sustenta e a natureza do feedback sobre si 
mesmo que você atrai mediante suas ações são exemplos do ambiente pessoal, ou espaços que você conscientemente ou inconscientemente define para si mesmo".

Na redução de 'relações sociais para relações humanas imediatas', a sociedade em que a experiência é apresentada permanece oculta, a parte está isolada do todo.

Central para a saúde holística e para os modelos de autocuidado é o conceito de responsabilidade individual. Essa noção aparece em praticamente tudo o que tem sido escrito sobre esses assuntos. Ardell 53 resume sua importância: "Todas as dimensões do bem-estar de alto nível são igualmente importantes, mas a responsabilidade por si mesmo parece mais comum que todo o resto. É a pedra filosofal, a bússola do marinheiro e o anel do poder para um estilo de vida com alto nível de bem-estar. Sem um senso ativo de responsabilidade pelo seu próprio bem-estar, você não vai ter a necessária motivação para conduzir um estilo de vida que melhore sua saúde”.

Responsabilidade individual é o mecanismo que se supõe impulsionar a transição de uma experiência medicamente dominada para uma manutenção e promoção da saúde mais significativa, autônoma e eficaz. Como tal, pode ser entendida como uma linguagem política. Essa responsabilidade estimula os indivíduos a resgatarem o poder que eles deram aos médicos. Mais cinicamente, pode também ser entendido como um dispositivo conveniente, por meio do qual um conjunto de curadores captura a clientela de outrem, enquanto obscurece o objetivo primário. Em uma sociedade medicalizada e 'reificada', na qual nos percebemos como meros objetos e as forças que nos envolvem como sujeitos ativos, a decisão de assumir a responsabilidade pessoal pode significar uma revitalização da tentativa de controlar essas forças, para nos tornarmos a nós mesmos sujeitos ativos. Além disso, obriga-nos a analisar a forma como temos nos tornado cúmplices em nossa própria opressão. Se não acreditarmos que podemos controlar nosso próprio destino, como qualquer mudança consciente pode ocorrer? Portanto, afirmar a reivindicação de responsabilidade individual deslegitima parcialmente as autoridades existentes e abre um novo terreno político. Na medida em que a responsabilidade individual e termos relacionados como o de autoajuda são experimentados como símbolos de empoderamento, podem tornar-se uma das poucas maneiras pelas quais as pessoas se imaginam como ativamente políticas ${ }^{10}$.

No entanto, como linguagem política, a responsabilidade individual é altamente problemática. De modo mais evidente, ela corre o risco de estar sujeita aos mesmos equívocos do individualismo clássico que venho discutindo, bem como de fomentar a ilusão de que a responsabilidade individual é suficiente. Dessa forma, também permanece em aberto a hipótese ‘voluntária' sobre o comportamento humano, através da qual se pressupõe que, porque indivíduos podem e escolhem agir de forma diferente, resta a eles, ao fim e ao cabo, fazerem escolhas. Em outras palavras, promove uma concepção que ignora as restrições sociais no 'ato da escolha'. Além disso, pode também exacerbar um sentimento de impotência já prevalente em relação ao controle sobre forças que incidem sobre os indivíduos, ao promover um conceito de controle que pode ser visto como uma alternativa à eficácia política: "Eu não posso mudar o mundo, mas pelo menos posso mudar a mim mesmo". Frente à desesperança de que "todas as coisas provocam câncer”, a proteção pessoal é oferecida como o melhor caminho para a saúde 54: "Temos evidências de que o câncer pode ser provocado pelo ar que respiramos, pelos alimentos que comemos, ou pelos pijamas que nossas crianças vestem para dormir. Uma vez que é claramente quase impossível evitar o contato com as causas de câncer conhecidas, as questões mais importantes tornam-se: Como é que vamos estimular e fortalecer a nossa resistência? Como podemos ativar o sistema imunológico?”

Além disso, para uma geração que experimentou o movimento político e a emoção da década de 1960, a virada para a vida interior em direção ao autocultivo pode ser parcialmente entendida como uma reação à decepção eimpotência políticas vividas na década de 1970. A redefinição do problema como autotransformação e preocupação consigo, em conservar-se saudável, é uma maneira de lidar com essa desilusão.

No possível reconhecimento de alguns destes problemas, o argumento foi que a responsabilidade pessoal é o primeiro passo necessário em direção a um estágio mais político, no qual as pessoas agirão coletivamente para mudar as condições sociais. "Consciência individual intensificada”, Katz e Levin afirmam²3, 
“é uma condição prévia para a ação social, e não antagônica a ela”. Eles oferecem a hipótese de que "pessoas atentas aos riscos pessoais e ativas em sua própria autoproteção são pessoas mais propensas a se preocuparem com etiologias econômicas e políticas”, e que: “[...] o potencial para aumentar a competência e a confiança dos cidadãos em combater os poderes estabelecidos é grande, sucessos pequenos e locais liderarão outros; coligações para fins políticos e sociais mais amplos ocorrerão [...]"23.

Mas, se a responsabilidade individual é entendida como conjunto de ações tomadas no nível individual para melhorar ou aliviar uma condição particular, não há nenhuma evidência de que uma concepção ou comportamentos mais políticos se seguirão. Claro, também não há evidência para a visão cética. Há estatisticamente uma correlação positiva entre um senso individual de eficácia pessoal, autoconfiança, autoestima, e assim por diante, e o nível de participação política e social ${ }^{54}$. Mas a relação é muito mais complexa do que a teoria da primeira etapa de responsabilidade individual para a ação política sugere. Não estou negando que, para muitos, uma concepção mais política possa coexistir ou suceder (nem estou questionando as medidas de proteção individual); estou questionando apenas a suposição não examinada. Afinal, a responsabilidade individual como ideologia tem muitas vezes funcionado historicamente como um substituto para compromissos políticos coletivos. Essas possibilidades de exclusão mútua podem não existir no presente caso? Dada a prevalência de noções privatizadas do caminho para o bem-estar, e a atual campanha ideológica para atribuir toda a responsabilidade pela saúde ao indivíduo ${ }^{19,20}$, uma teoria de estágio de politização é questionável. Na verdade, a falha em adotar um entendimento explicitamente político do problema de saúde soma-se à recusa em enfrentar a despolitização maciça e ideológica que está sendo promovida. Isso equivale a garantir que a ideologia dominante prevalecerá.

Finalmente, como empregada atualmente, a noção de responsabilidade individual promove uma suposição de culpa do indivíduo. A interseção da moralidade e da culpa com doença e saúde é um dos temas mais complexos enfrentados por sociólogos e médicos historiadores sociais ${ }^{25,26,28,45,56-60}$. Saúde e doença têm sido sempre conceitos morais e não podem ser compreendidas independentemente dos princípios morais da época nem das relações sociais particulares em que estão colocadas, incluindo a relação médico-paciente. Ehrenreich e English ${ }^{61}$ e Ehrenreich ${ }^{62}$ têm tentado mostrar, por exemplo, como as estruturas patriarcais e os valores são emitidos pela estruturação médica da doença como uma espécie de desvio. Claramente, o clássico papel parsoniano de doente não é suficiente como explicação adequada. Parsons ${ }^{63}$ acreditava que o papel de doente é um processo social pelo qual o enfermo não seria responsabilizado ou punido pelo desvio das obrigações do papel social normal, desde que não cedesse à doença, mas concordasse em trabalhar com os profissionais médicos, a fim de ser capaz de retornar o mais rápido possível a essas obrigações. Ele pensou que a 'isenção' contida no papel de doente era uma forma ideal convencional. Em contraste com a doença vista principalmente como punição ou como evidência de projetos satânicos, a medicina (enquanto ainda realiza importantes objetivos de controle social) oferece uma interpretação mais benigna. Em alguns aspectos, a doutrina médica de etiologia específica - a identificação de uma causa externa, natural, biológica - de fato promove um aparente afastamento da moralização da doença e da enfermidade. Ela concede uma isenção, embora julgamentos morais submersos persistam, tanto na relação médico-paciente, quanto na cultura popular.

O salutarismo, no entanto, adota um moralismo mais estridente. Acompanhando o foco sobre o que podemos fazer por nós mesmos como indivíduos, a culpa é trazida para a frente do palco ${ }^{\text {viii }}$. Responsabilidade por si não é necessariamente igual a culpa. Como ideologia, no entanto, que se concentra tão exclusivamente no comportamento, na motivação e no estado emocional, e como uma ideologia de autoaperfeiçoamento que insiste que a mudança e a saúde derivam das escolhas individuais, a saúde ruim é mais provavelmente vista como decorrente de falhas individuais. "Nós escolhemos a nossa doença, quando, por negligência ou ignorância,

viii Aqui, salutarismo também reflete (e dá apoio adicional para) as recentes mudanças no modelo médico. O desenvolvimento da Medicina Psicossomática já estabeleceu as bases para o novo moralismo e para sua legitimação científica. 
permitimos que ela se espalhe dentro de nós" ${ }^{4}$, ou "não devemos nos enganar, pensando que a doença é causada por um inimigo de fora. Somos responsáveis pela nossa doença”63. Como o estresse torna-se um paradigma dominante “os clientes são ajudados na compreensão de como eles são responsáveis pelas pressões e tensões em suas vidas” Alertados contra o pensamento sobre o estresse como um fator "patogênico de fora", somos informados de vez que o estresse depende de nós ${ }^{50}$. "Falamos sobre o estresse produzido pelos nossos empregos, nossa casa, nossa família, nosso negócio, o tempo, o governo, as condições do mundo, e assim por diante. Mais uma vez, somos levados a acreditar que somos vítimas de alguma força exterior que impõe sua vontade, causando-nos sofrimento [...] Nós escolhemos nossa própria patogênese de estresse patológico pela forma como escolhemos perceber e interpretar os acontecimentos em nossas vidas".

E como saúde se torna um supervalor, aqueles que falham em buscá-la tornam-se semelhantes a párias ${ }^{47}$ : "O dom da saúde é um dom de vida, o que aumenta o valor de toda a ideia exponencialmente. O dom da saúde, então, é o dom da felicidade, de completude, de amor e do ser. Abusar dela, deixar de procurá-la com o nosso poder é uma negação do valor do self. Qualquer um que ignore a magnificência da vida merece apenas piedade”.

Assim, a incapacidade de manter a saúde é atribuída a algum tipo de indisponibilidade para estar bem ou a um desejo inconsciente de estar doente, ou simplesmente a uma falha. Conforme afirmado por Ardell53: "O único tirano que você enfrenta é a sua própria inércia e ausência de vontade, sua crença de que você está ocupado demais para ter o seu próprio bem-estar em suas mãos e que buscar saúde individual por meio de um estilo de vida que promova bem-estar é muito difícil, complicado ou inconveniente".

Às vezes, a falha em manter a saúde é explicada pela ignorância ou pela incapacidade para assegurar suporte social imediato para a mudança individual.

Em outras palavras, o princípio de nenhuma culpa contido na formulação do papel clássico de doente, em si uma falsificação, está sendo substituído pelo dogma 'é sua culpa'. Nas palavras de um adepto65: "Como um pré-requisito para a saúde holística nós devemos: parar de culpar os outros por nossa condição ou esperar que os outros nos salvem de problemas". O salutarismo se junta a outras forças sociais que atualmente atacam o que consideram ‘excesso' ou 'abuso' da doença como uma desculpa para evitar 'obrigações', desnecessariamente visitar um médico, coletar benefícios do governo ou benefícios negociados.

Os salutaristas, assim, ajudaram a criar um 'papel de doente potencial' através do qual a obrigação de ficar saudável é mais fortemente afirmada. No papel de doente potencial, as expectativas da sociedade são impostas em nome da prevenção. Como potencialmente doentes, os indivíduos estão enfrentando pressões sociais mais intensas para agir de forma a minimizar esse potencial. Falhar em agir preventivamente torna-se um sinal de irresponsabilidade 'social', não apenas individual. De acordo com Knowles ${ }^{66}$ : “A ideia de responsabilidade individual tem sido submersa em direitos individuais - direitos ou demandas a serem garantidos pelo governo e entregues pelo público e instituições privadas. O custo da preguiça, gula, intemperança alcoólica, direção imprudente, frenesi sexual e do fumo, é, agora, uma responsabilidade nacional, e não individual”. "Isso é justificado como liberdade individual, mas a liberdade do homem em relação à sua saúde é sua prisão em impostos e prêmios de seguro. Acredito que a ideia de um ‘direito’ de saúde deve ser substituída pela ideia de uma obrigação moral individual para preservar a própria saúde, um dever público, se você quiser".

A noção de desvio é, portanto, estendida desde o doente ao potencialmente doente, de uma doença manifesta ao que é considerado um comportamento não saudável. Nós todos nos tornamos desviantes em nossa vida cotidiana, quando acendemos um cigarro, quando consumimos ovos no café da manhã e quando não somos capazes de expressar nossas emoções. Pessoas que agem de tal forma a predisporem-se à doença já são consideradas atualmente doentes ${ }^{67}$. "Bem-estar positivo, e não apenas a ausência de doença, é a meta. O médico convencional considera que uma pessoa está bem se ela não tem sintomas e cai dentro da normalidade de alcance de uma série de testes de diagnóstico. No entanto, esta pessoa que está 'bem’ pode fumar muito, não fazer exercícios, ter uma dieta pobre, baseada em doces e amido, e impressionar a todos que a encontram por ainda ser triste, antissocial 
e emocionalmente deprimida. Para um praticante da Nova Medicina, tal pessoa está muito doente, portadora do que o biólogo René Dubos chama de “doença potencial submersa”.

Assim, todos os comportamentos, atitudes e emoções considerados 'de risco' para o indivíduo são medicalizados - rótulos de saúde e doença tornam-se anexados a eles. Assim como o papel de doente, o papel de doente potencial ordena um dever moral: a obrigação de corrigir hábitos pouco saudáveis. Reciprocamente, condena a doença como uma falha moral individual. A isenção parcial contida no papel de doente é ainda comprometida. Noções de boa motivação e moralidade recuperam o status explícito. Doença, de novo, torna-se culpa individual. Nesse processo, a ideologia da vítima culpada ganha um poderoso aliado na cultura popular.

\section{A unidimensionalização do bem-estar}

bem-estar é divertido, romântico e moderno - É sexy e gratuito slogan de camiseta da saúde holística

No salutarismo, o comportamento saudável tornou-se o paradigma para a boa vida. Homens e mulheres saudáveis tornam-se modelos ideais de homens e mulheres. Um tipo de reducionismo ou unidimensionalização parece ocorrer entre os salutaristas: mais e mais experiências desembocam na experiência de saúde, cada vez mais os valores são valores de saúde. Saúde ou seu superlativo - 'supersaúde' - subsume uma panóplia de valores: 'uma sensação de felicidade e propósito', 'um alto nível de autoestima', 'satisfação no trabalho', 'capacidade para se expressar criativamente', 'capacidade de funcionar eficazmente sob estresse', 'ter confiança no futuro', 'um compromisso com viver no mundo', habilidade 'para celebrar a vida' ou mesmo 'afirmação cósmica'. "Saúde é mais do que a ausência de doença”, escreve um dos novos pregadores ${ }^{50}$, "que inclui uma vida totalmente produtiva, autorrealizada, expandida de alegria, felicidade e amor por qualquer coisa que se faça". Na ética do "alto nível de bem-estar", a saúde é a liberdade no verdadeiro sentido - de liberdade sem objetivo -, ser capaz de expressar uma série de emoções livremente, um "entusiasmo pela vida"68. Em suma, a saúde tornou-se não só uma preocupação, mas também um valor supremo ou padrão pelo qual um número crescente de comportamentos e de fenômenos sociais é julgado. Menos um meio para a realização de outros valores fundamentais, a saúde assume a qualidade de um fim em si. A boa vida é reduzida a um problema de saúde, assim como a saúde é ampliada para incluir tudo o que é bom na vida.

Noprocesso deaquisiçãodeumaidentidadegovernada pela saúde, o mundoéreestruturado metafisicamente e politicamente. Como a simbologia da saúde se expande para incluir mais e mais experiências, experiências de outros tipos são afetadas - simbolizações alternativas pelas quais as pessoas definem seu mal-estar e seus objetivos, juntamente com estratégias implícitas para o alívio ou realização. Outras percepções são reordenadas em relação ao símbolo da saúde e tornam-se subordinadas a ele. Tais percepções se tornam mais remotas, menos parte da compreensão e preocupação conscientes, ou, alternativamente, mais imediatas, porém apenas em relação às noções culturalmente definidas do que significa ser saudável. Mais valores são incorporados sob a rubrica de saúde e, assim, perde-se a clareza de distinção do que é saudável.

A saúde tem sido periodicamente proeminente na imaginação utópica. Três décadas atrás, a Organização Mundial da Saúde (OMS) aprovou uma definição de saúde que permanece como um precursor do significado contemporâneo para o conceito: "Saúde é um estado de completo desenvolvimento de bem-estar físico, mental e social e não meramente a ausência de doença ou enfermidade". Um crítico, Daniel Callahan ${ }^{69}$, escreveu sobre essa definição: "verifica-se o problema da felicidade humana como mais um problema médico a ser tratado por meios científicos. Isso torna a profissão médica a guardiã da felicidade e do bem-estar social, o curador mágico último da miséria humana". Os problemas permanecem, mas agora os curadores são holísticos e a busca pela saúde é uma preocupação cotidiana. Callahan ${ }^{69}$ posiciona o problema de forma clara na sua elaboração de objeções à definição da OMS: "Tal ideologia tem o efeito prático de dificultar a responsabilidade adequada. Se todos os problemas 
- políticos, econômicos e sociais - se reduzem a questões de 'saúde', então deixa de haver alguma maneira de determinar quem deve ser responsável pelo que [....] Pois na medida em que se tratam as desordens humanas - guerra, crime, agitação social - como formas de doença, então [...] saúde não é mais um assunto opcional, mas a chave de ouro para o alívio da miséria humana”.

É aqui que a noção medicamente construída de saúde como assunto pessoal ou individual - como um problema que surge a partir de fatores internos ou nos limites do corpo individual - volta a ser considerada. Sob tal simbologia, a luta pelo bem-estar generalizado, definido como saúde, torna-se mais firmemente presa aos limites de esforço pessoal. Considerando que a medicina individualiza a 'doença', o salutarismo individualiza o 'mal-estar'. Ou se defende a reparação terapêutica e a blindagem, ou adota-se uma estratégia independente para o aprimoramento pessoal contra as forças externas e fraquezas internas que ameaçam o bem-estar. No mundo dos salutaristas, a busca de saúde substitui o, ou pode ser definida como, exercício político. Onde é mais provável que trabalhadores braçais falem de aceleração do ritmo de produção ou longas horas de trabalho, salutaristas de classe média estão mais propensos a discutir o seu equilíbrio interno, estresse ou mecanismos adaptativos. O estresse está em você; a exploração está nos outros.

Uma série de fatores que contribuem para este resultado pode ser sugerida. Como valor supremo ${ }^{\text {ix }}$ que a tudo perpassa, o salutarismo é uma forma de medicalização. A propaganda médica tem bombardeado nossa cultura com a mensagem de que a saúde é o mais importante dos valores, oferecendo pílulas mágicas como a chave para uma vida mais longa e livre de doenças. Os próprios médicos fazem uso das pílulas e alçaramse à condição de heróis culturais. Produtos médicos inundaram os meios de comunicação. Não deve ser nenhuma surpresa que o fracasso da medicina em realizar a promessa não acaba com o sonho. Exatamente o oposto. A saúde tornou-se ainda mais que uma fixação, englobando não só os produtos terapêuticos, atividades e imaginação de um conjunto de novos terapeutas em expansão, mas também a preocupação cotidiana e a atenção da classe média.

A promoção e o controle da saúde pessoal encontram terreno fértil em uma população de classe média, que em 1970 foi obrigada a se adaptar a um mundo de aumento da insegurança e da incerteza, na saúde, na vida econômica e nos relacionamentos pessoais. Quando a vida é experimentada como ilusão de controle, especialmente quando as pessoas começam a se perguntar se um padrão de vida a que se acostumaram pode ser sustentado, a necessidade de um controle pessoal é intensificada. Saúde pessoal tem se tornado uma das áreas em que as pessoas podem concentrar suas energias e reafirmar o sentido de que elas podem agir por si próprias.

Além disso, como somos cada vez mais definidos como desviantes (como potencialmente doentes) em nossos comportamentos cotidianos, atitudes e sentimentos, passamos a nos ver como estando em falta. Não só podemos experimentar a insegurança da doença futura imaginada, a ansiedade de alguns prognósticos preocupantes, mas também a insegurança do desvio, a ansiedade de não nos encaixarmos no padrão. Adotar a saúde como um valor em que se concentram as preocupações pode servir como uma espécie de proteção contra a insegurança. O salutarista em essência diz: 'Veja, eu não sou desviante. Eu não estou em falta. Eu controlo minha condição. Eu estou no processo de ser saudável por inteiro'. O que é importante é a adoção de um símbolo como uma identidade pessoal, que corresponde às expectativas sociais dominantes e está em oposição à identidade do desviante. O salutarismo, em outras palavras, garante sua própria reprodução contínua. Estende o desvio e, em seguida, fornece uma resposta ao seu próprio problema. Além disso, apesar do aparente individualismo, por fazer da saúde um supervalor e, em seguida, definir a saúde como um conjunto distinto de comportamentos, atitudes e emoções, uma estruturação mais social da experiência é promovida. O salutarismo pode, dessa forma, ser uma resposta não somente à própria extensão do desvio, mas também ao isolamento em um sentido mais amplo: 'Se estamos ficando sozinhos, pelo menos vamos

ix NT: o termo original é pan-valor. 
ficar sozinhos da mesma forma; fazer as mesmas coisas etc.'. Assim, o individualismo do salutarismo pode, na verdade, ser uma afirmação altamente elaborada de pertença.

Ironicamente, no entanto, o salutarista é forçado a uma contradição profunda. Por um lado, ele adota o símbolo de saúde como seu. Por outro lado, enquanto ele mergulha mais profundamente na definição sem limites da saúde como total bem-estar, a doença torna-se cada vez mais uma experiência cotidiana consciente. O bem-estar total gera total mal-estar. O salutarismo pode, assim, reforçar a experiência do indivíduo como um desviante e a ansiedade de uma sensação de falha para a qual é exigido um comportamento cada vez mais compensador. Provavelmente estende a apreensão sobre a doença futura também. Apesar dos rituais compartilhados de busca salutarista, como superar o isolamento nessas circunstâncias?

Mais gravemente, quando a boa vida for definida como eliminação dos sintomas pessoais considerados contrários à saúde, emergirá uma espécie de protecionismo individualista de um suposto estado estabilizado (acredita-se que o sistema psicobiológico seja derivado de uma vida estável) em que qualquer alteração produzirá conflitos, chateações e aumento de estresse, tudo o que se acredita levar a doenças terríveis aos 40 anos, portanto?

O que vão fazer os salutaristas, por exemplo, $\operatorname{com} \operatorname{dados}^{70}$ que sugerem "uma relação entre a rápida mudança social e mudanças pessoais correspondentes, incluindo situações desordenadas, que levam eventualmente à doença?” No seu extremo, a alienação e seus comportamentos relativos se tornarão doença (entendida como doença potencial) e a integração e seus comportamentos relativos (aquiescência feliz) serão celebrados no altar da saúde? O salutarismo se tornará a ideologia perfeita para uma cultura despolitizada e encapsulada?.

Deixando os piores medos de lado, o argumento aqui é que o salutarismo serve para mistificar e canalizar o descontentamento e, talvez, o desvio em si $^{72}$, em formas que são basicamente não ameaçadoras à ordem existente. A medicina sempre exerceu esta função de controle social e agora a ideologia medicalizada faz o mesmo. Se o conflito ideológico pode ser pensado como uma luta por sistemas de símbolos pelos quais as pessoas definem seu mal-estar e que implicam determinadas soluções, o símbolo de saúde na ideologia salutarista emergente é mais compatível com um sistema de dominação baseado na terapêutica e na realização pessoal de bem-estar. Assim como a linguagem de cuidado ou ajuda obscurece as relações desiguais de poder em um Estado terapêutico crescente ${ }^{73}$, também a linguagem de autocuidado, de responsabilidade individual e de holismo obscurece as relações de poder que subjazem à produção social da doença e do descontentamento.

x "O individualista supremo - oposto em profundidade aos modos antigos da própria salvação: através de identificação com o propósito comunal", é nos termos de Rieff46 o "homem psicológico", uma nova personalidade modal que mantém sua convicção que "o novo centro, que pode ser mantido até mesmo quando as comunidades se desintegram é o eu (self)". O triunfo da terapêutica significou, para Rieff, a derrota da política. Veja também Lasch ${ }^{71}$. 


\section{Saúde e subjetividade}

Minha tese tem sido de que os movimentos de nova consciência em saúde estão em perigo de ser capturados pela simbologia e pela prática da pura subjetividade. Não é que a mudança social seja completamente ignorada, só que ela é vista como um resultado da prática subjetiva multiplicada. Mudanças ocorrerão, acredita-se, como no mercado, quando uma quantidade suficiente de pessoas for reconhecida pelos centros de poder como desejando e escolhendo estilos de vida saudáveis. Muitas vezes, uma avaliação pessimista da oportunidade para a mudança política reforça ideias utópicas de mudanças a longo prazo com base em escolhas individuais.

Considerando a dificuldade de mudar estilos de vida (por exemplo, o hábito ou vício de fumar, ou o investimento de tempo e dinheiro necessários para encontrar produtos saudáveis) é notável que haja tanto interesse em fazê-lo. O foco comportamental torna-se mais compreensível, no entanto, em um contexto no qual proteção e promoção de saúde pessoal parecem ser a única alternativa possível para um ambiente negador de saúde, que escapa ao controle. Diante de tais escolhas limitadas, o mais difícil será tentar ajustes individuais. Na ausência de uma clara responsabilidade social para (ou compromisso com) a promoção de saúde, a responsabilidade individual vem a ser vista como uma necessidade. Como indivíduos, enfrentamos o mesmo dilema: não podemos nos permitir esperar por uma solução política, então acreditamos que aqueles de nós que são capazes de adotar práticas de saúde reduzirão seus riscos. A perda de controle sobre a saúde é ‘amainada pela sua busca interminável'.

Os mais capazes de fazer ajustes individuais têm mais probabilidade de pertencer à classe média. Pessoas de classe média não só possuem mais recursos pessoais para a mudança de estilo de vida, fazendo terapia holística, e assim por diante, mas também adquiriram noções fundamentais sobre si mesmos como atores sociais a partir de situações de trabalho (e todo o apoio de padrões de socialização) que são individualmente competitivas. Eles já estão predispostos a verem suas conquistas como resultados de um esforço pessoal solitário. Uma formulação salutarista, ainda que plausível, é menos propensa a ser a resposta dos trabalhadores braçais e de pessoas de classes inferiores, que estariam mais inclinados a ver ao menos alguns problemas de saúde em termos de nós e eles ${ }^{\mathrm{xi}}$.

Os vários movimentos de saúde tomaram direções muito diferentes. Ativistas políticos dos movimentos de saúde ocupacional e ambiental são os únicos a atribuírem ênfase sobre os fatores externos que incidem sobre o indivíduo - fatores objetivos, como a produção corporativa de cancerígenos que são ameaças concretas à saúde enquanto salutaristas nos movimentos de autocuidado e de saúde holística estão preocupados com a área subjetiva, comportamental. Ambos transformam as verdades fundamentais em meias verdades através de uma atenção exclusiva. Um enxerga o indivíduo como problema, o outro enxerga a sociedade como problema. Ambos não conseguem entender o que Marx compreendeu ( apud Jacoby35): “Acima de tudo devemos evitar postular 'Sociedade', mais uma vez, como uma abstração vis-à-vis ao indivíduo. O indivíduo ‘é o ser social' "(destaque no original)”.

As ideias de Russell Jacoby ${ }^{35}$ são pertinentes neste ponto: “Asubjetividade prevalentenãoéum oásis em uma sociedade estéril e desumanizada; de outro modo, está estruturada até o seu núcleo pela própria sociedade que imagina ter deixado para trás. Para aceitar a subjetividade como existe hoje, ou melhor, como não existe hoje, está implícito aceitar a ordem social que a mutila. O ponto, no entanto, não é meramente rejeitar a subjetividade, [...] é se aprofundar na subjetividade seriamente. Esta seriedade implica compreender até que ponto a subjetividade prevalente é ferida e mutilada; esse entendimento significa mergulhar na subjetividade não apenas para louvá-la em profundidade, mas para avaliar o dano, o que significa procurar as configurações sociais objetivas que reprimem e oprimem o sujeito. Só dessa forma a subjetividade pode ser percebida: compreendendo até que ponto ela está objetivamente atrofiada".

O fracasso dos movimentos de saúde ocupacional e ambiental, bem como da esquerda política, em desenvolver uma crítica e prática que leve a sério o dilema dos indivíduos (por exemplo, as necessidades de opções viáveis e de

xi Ehrenreich ${ }^{74}$ discute um sentido no qual o salutarismo pode ser uma expressão de uma mentalidade "nós-eles". Ela sugere que o salutarismo tem se tornado um importante meio para estruturar a identidade de classe, comportamentos manifestos de promoção da saúde (por exemplo, não fumar) podem atuar como "sinais de reconhecimento", para fins tanto de diferenciação como de afirmação mútua. 
estratégias imediatas para reduzir a vulnerabilidade às doenças, ou de modos de cura mais viáveis e significativos) prejudica a realização de seus objetivos. Pelo menos o salutarismo 'tenta' responder a essas necessidades. Nesse sentido, ele é manifestamente terapêutico.

A pura subjetividade, no entanto, não pode evitar a promoção de um equívoco entre as condições subjetivas e objetivas de saúde e doença. Ela não contempla a essência dialética da existência social. O isolamento imposto sobre os dois reinos, subjetivo e objetivo, é político e ideológico; serve aos interesses de dominação. O fracasso da ideologia salutarista para tratar o comportamento individual, atitudes e emoções como socialmente construídos reproduz a incapacidade promovida pela ideologia médica e pela ideologia do individualismo em geral. Em vez de abordar a complexa interação entre características individuais, escolhas e a estrutura social mais ampla, o salutarismo promove um novo moralismo.

Todos precisam lidar com dificuldades. Diante de situações desesperadoras aparentemente imutáveis, inventamos maneiras de adaptarmo-nos a elas, apesar das consequências muitas vezes incapacitantes de muitos dos mecanismos de enfrentamento que 'escolhemos'. Sem esses mecanismos, abundantemente fornecidos no interesse do controle social, esta sociedade iria explodir com descontentamento. Para aqueles de nós que buscam a mudança política e pessoal, as formas de enfrentamento colocam, frequentemente, obstáculos que parecem intransponíveis. Mas seria romantismo puro, bem como moralismo elitista, insistir que desistamos de nossos modos de lidar, que paremos de nos adaptar e sigamos com a atitude de mudar a nós mesmos e o mundo. Tal moralismo não vai derrotar a ausência de política. A maioria das pessoas vai escolher a mudança em situações em que faz sentido para elas assim fazê-lo.

O salutarismo é uma espécie de moralismo elitista no qual se acredita não ser saudável o comportamento de enfrentamento. É irônico que salutaristas devam ser tão puritanos. Pois, embora se oponham a um tipo de enfrentamento, adotam outro tipo de filosofia que também incapacita. Em seu foco exclusivo na prática subjetiva, reproduzem a mesma dinâmica de resposta que os comportamentos de risco que estão criticando. Minha crítica ao salutarismo não visa questionar se ele tem algum valor terapêutico. Qualquer coisa que favoreça o indivíduo não pode ser descartada. Assim, embora salutaristas advoguem mudanças de comportamento que, como deixar de fumar ou reduzir o consumo de álcool, são suscetíveis de melhorar a saúde individual, a longo prazo, essa preocupação exclusiva é passível de 'negar' a saúde. Reforça a ilusão de que o enfrentamento individual é suficiente. Certamente é possível enfrentar e mudar a si mesmo e a sociedade ao mesmo tempo. Mas porque enfraquece ainda mais a concepção política do problema de saúde, o salutarismo reforça a tendência às soluções privadas e individuais.

Uma sociedade de risco irá produzir indivíduos em situação de risco e comportamentos de risco. O próprio salutarismo deixa as pessoas em risco. A verdadeira saúde holística exige uma sociedade holística. Um movimento que espera transformar o comportamento humano deve ir além da estratégia de remediar. É necessário que haja uma ideologia e prática que, ao contrário do salutarismo, procure melhorar a nossa capacidade social para controlar as condições de nossa existência. Similarmente, os movimentos políticos com o objetivo de mudar as condições sociais não saudáveis seriam mais bem-sucedidos se levassem a sério as necessidades individuais de lidar com a questão, para encontrar soluções parciais para si próprios. Deve ser superada a separação ideologicamente imposta e paralisante entre ações de enfrentamento privadas, pessoais e aquelas de movimentos políticos destinados a mudar a sociedade, para que uma estratégia viável de saúde e uma sociedade viável sejam conquistadas. O salutarismo incapacita porque a capacidade humana não pode avançar apenas na esfera subjetiva. ${ }^{\text {xii }}$

xii Para mim, escrever é realmente um processo coletivo, bem como um processo individual. Muitas pessoas têm respondido aos meus projetos e apresentações pessoais para citá-los individualmente. Obrigado a cada um. Este artigo teria sido melhor se tivesse aproveitado mais suas sugestões. 


\section{Referências}

1. Gordon J. The paradigm of holistic medicine. In: Hastings A, Fadiman J, Gordon J, organizers. Holistic medicine. Bethesda: National Institute of Mental Health; 1979.

2. Guttmacher S. Whole in body, mind and spirit: Holistic health and the limits of medicine. Hastings Cent Rep. 1979 Apr; 9(2):16-21.

3. Berliner $\mathrm{H}$, Salmon J. The holistic health movement and scientific medicine: The naked and the dead. Socialist Rev. 1979; 43:31-52.

4. Sobel D. Ways of health: holistic approaches to ancient and contemporary medicine. New York: Harcourt Brace Jovanovich; 1979.

5. Kaslof L. Wholistic dimensions in healing. New York: Doubleday; 1978.

6. Popenoe C. Wellness. Washington: Yes Inc.; 1977.

7. Berkeley Holistic Health Center. The holistic health handbook: a tool for attaining wholeness of body, mind, and spirit. Berkeley: And/Or Press; 1978.

8. Bricklin M. The practical encyclopedia of nature healing. Emmaus, Pa: Rodale Press; 1976.

9. Katz A, Bender E. The strength in US: self-help groups in the modern world. New York: New Viewpoints; 1976.

10. Gartner A, Riessman F. Self-help in the human services. San Francisco: Josey-Bass; 1977.

11. Levin L, Katz A, Holst E. Self-care: lay initiatives in health. New York: Neale Watson; 1976.

12. Special Self-Help Issue. Soc Policy. 1976;7(2).

13. Med Self-Care, [197-?];1-7.

14. Kronenfeld J. Self care as a panacea for the ills of the health care system: an assessment. Soc Sci Med 1979; 13A:263-67.

15. Self-Help and health: a report. New York: New Human Services Institute, Queens College, City University of New York; 1976.

16. Ozonoff V, Ozonoff D. On helping those who help themselves. Hastings Cen Rep. 1977;7(1):7-10.

17. Levin L. The layperson as the primary care practitioner. Public Heal. 1976; Rep. 91:206-10.

18. Boston women's health book collective. Our bodies, ourselves. 2nd ed. New York: Simon and Schuster; 1976.

19. Crawford R. You are dangerous to your health: the ideology and politics of victim blaming. Int J Health Serv. 1977; 7(4):663-80.

20. Crawford R. You are dangerous to your health: the ideology and politics of victim blaming. Social Pol. $1978 ; 8(4): 10-20$.

21. Patrick $D$, Elinson J. Methods of sociomedical research. In: Freeman $H$, Levine $S$, Reeder $L$, organizers. Handbook of medical sociology. Englewood Cliffs, N.J.: Prentice-Hall; 1979.

22. Zola I. Healthisrn and disabling medicalization. In: Illich I, Zola IK, Mcknight J, organizers. Disabling Professions. London: Marion Boyars; 1977.

23. Katz A, Levin L. Self care is not a solipsistic trap: a reply to critics. Int J Health Serv. 1980; 10(2):329-36.

24. Belloc N, Breslow L. Relationship of physical health status and health practices. Prev Med 1972; 1(3):409-21.

25. Rosenberg $\mathrm{C}$. The therapeutic revolution: medicine, meaning and social change in nineteenth-century America. In: Vogel M, Rosenberg C, organizers. The therapeutic revolution. Philadelphia: University of Pennsylvania Press; 1979.

26. Freidson E. Profession of medicine. New York: Dodd, Mead and Company; 1972.

27. Illich I. Medical nemesis: the expropriation of health. New York: Pantheon; 1975. 
28. Rosenberg C. No other gods. Baltimore: Johns Hopkins University Press; 1961.

29. Dubos R. The mirage of health. Garden City, NY: Anchor Books; 1961.

30. Szasz T. The theology of medicine. New York: Harper Colophon Books; 1977.

31. Zola I. Medicine as an institution of social control. Sociol Rev. 1972; 20(4):487-504.

32. Stone D. Diagnosis and the dole: the function of illness in American Distributive Politics. J Health Polit Policy Law. 1979:4(3):507-21. doi: https://doi.org/10.1215/03616878-4-3-507

33. Conrad P; Schneider J. Deviance and medicalization: from badness to sickness. St. Louis: CV. Mosby; 1980.

34. Swenson N. Review [de Self-care: lay initiatives in health. L Levin, A Katz, E Holst]. Soc Sci Med $1978 ; 12(3 \mathrm{~A}): 86-188$.

35. Jacoby R. Social amnesia: a critique of contemporary psychology from Adler to Laing. Boston: Beacon Press; 1975.

36. Foucault M. The birth of the clinic: an archaeology of medical perception. New York: Pantheon; 1973.

37. Rosen $G$. The evolution of social medicine. In: Freeman $H$, Levine $S$, Reeder $L$, organizers. Handbook of medical sociology. 3rd ed. EngIewood Cliffs, NJ: Prentice-Hall; 1979. p. 23-50.

38. McKeown T. The role of medicine: dream, mirage, or nemesis. London: Nuffield Provincial Hospitals Trust; 1976.

39. Carlson R. The end of medicine. New York: John Wiley \& Sons; 1975.

40. Lalonde M. A new perspective on the health of Canadians. Ottawa: Information Canada; 1975.

41. McKinlay J, McKinlay S. The questionable contribution of medical measures to the decline of mortality in the U.S. in the twentieth century. New York: Milbank Mem Fund Q; 1977. p. 405-28;

42. Kleinman A, Eisenber J, Good B. Culture, illness, and care: clinical lessons from anthropologic and crosscultural research. Ann Intern Med. 1978;88:251-58.

43. Dewar T. The professionalization of the client. Social Pol. 1978;8(4):4-9.

44. McKnight J. Professionalized service and disabling help. In: Illich I, Zola IK, Mcknight J, organizers. Disabling Professions. London: Marion Boyars; 1977.

45. Taussig M. Reification and the consciousness of the patient. Soc Sci Med 1980;14(B):3-13.

46. Rieff P. The triumph of the therapeutic. New York: Harper Torchbooks; 1966.

47. Grant L. The holistic revolution. Pasadena, Ca.: Ward Ritchie Press; 1978.

48. Hayes-Bautista D, Harveston D. Holistic health care. Social Pol. 1977;7(5):7-13.

49. Miles R. Humanistic medicine and holistic health care. In: Berkeley Holistic Health Center, organizer. The holistic health handbook. Berkeley And/Or Press; 1978. p. 20-24.

50. Goldwag E. The dilemma in health care. In: Goldwag E, organizer. Inner balance: the power of holistic healing. Englewood Cliffs, NJ: Prentice Hall; 1979. p. 10-27.

51. Bauman E. Introduction to holistic health. In: Berkeley Holistic Health Center, organizer. The holistic health handbook. Berkeley: And/Or Press; 1978. p. 17-19.

52. Simonton C, Matthews-Simonton S, Creighton J. Getting well again. Los Angeles: JP Tarcher Inc.; 1978.

53. Ardell D. High level wellness: an alternative to doctors, drugs, and disease. Emmaus, Pa: Rodale Press; 1977.

54. Oyle I. The new American medicine show. Santa Cruz, Ca.: Unity Press; 1979.

55. Milbrath J, Goel M. Political participation. Chicago: Rand McNally; 1977.

56. Haley B. The healthy body and victorian culture. Cambridge: Harvard University Press; 1978.

57. Roth J. Some contingencies of the moral evaluation and control of clientele: the case of the hospital emergency service. Am J Sociol. 1972 Mar;77:839-56. 
58. Sontag S. Illness as metaphor. New York: Farrar, Straus and Giroux; 1977.

59. Sedgwick P. Illness-mental and otherwise. Hastings Cen Stud. 1973;1(3):19-40.

60. Siegler M, Osmond H. The "sick role" revisited. Hastings Cen Stud. 1973;1(3):41-58.

61. Ehrenreich B, English D. For her own good: 150 years of the expert's advice to women. Garden City, NY: Anchor Press/Doubleday; 1978.

62. Ehrenreich J. The cultural crisis of modern medicine. New York: Monthly Review Press; 1978.

63. Parsons T. The social system. Glencoe, Ill: The Free Press; 1951.

64. Muramoto N. Healing ourselves. New York: Avon Books; 1973.

65. Neev E. Wholistic healing. Beverly HiIls, Ca: Ageless Books; 1977.

66. Knowles J. The responsibility of the individual. New York: Norton; 1977. Doing better and feeling worse: health in the United States. p. 57-80.

67. Leonard G. The holistic health revolution. New West; 1976 May 10.

68. Ardell D. Talk given to suburban health systems agency. Woodstock, Ill: Autumn; 1978.

69. Callahan D. The WHO definition of health. Hastings Cen Stud. 1973;1(3):77-87.

70. Graham S, Reeder L. Social epidemiology of chronic diseases. In: Freeman H, Levine S, Reeder L, organizers. Handbook of Medical Sociology. 3rd ed. Englewood Cliffs, NJ: Prentice-Hall; 1979. p. 71-96.

71. Lasch C. The culture of narcissism. New York: WW Norton; 1978.

72. Cloward R, Piven F. Hidden pretest: the structuring of female deviance. Signs. 1979;4(4):651-69.

73. Edelman M. The political language of the helping professions. Polit Soc. 1974;4(3):295-310.

74. Ehrenreich B. Talk given at the Annual Meeting of the American Public Health Association. New York; Nov 1979. 